\title{
Maternal Smoking, Intrauterine Growth Restriction, and Placental Apoptosis
}

\author{
Christina Vogt IsAKsen, ${ }^{1,2 *}$ Rigmor Austgulen, ${ }^{3}$ Lisa CHedWick, ${ }^{4}$ \\ Pål Romundstad, ${ }^{5}$ Lars Vatten $^{5}$, and Catherine Craven ${ }^{\dagger}$
}

\author{
${ }^{1}$ Department of Pathology and Medical Genetics/National Center for Fetal Medicine, St. Olav's Hospital, 7006, \\ Trondheim, Norway \\ ${ }^{2}$ Department of Laboratory Medicine, Children's and Women's Health, Faculty of Medicine, Norwegian University \\ of Science and Technology, Trondheim, Norway \\ ${ }^{3}$ Institute of Cancer Research and Molecular Biology, Norwegian University of Science and Technology, \\ Trondheim, Norway \\ ${ }^{4}$ Magee-Womens Research Institute, University of Pittsburgh, Pittsburgh, PA, USA \\ ${ }^{5}$ Institute of Community Medicine and General Practice, Norwegian University of Science and Technology, \\ Trondheim, Norway
}

Received October 3, 2003; accepted March 2, 2004; published online September 16, 2004.

\begin{abstract}
Pregnant women who smoke are at greater risk of delivering a growth-restricted infant than nonsmoking mothers. We wanted to see if apoptosis could be involved in the mechanisms behind smoke-induced growth restriction, and our aim was to compare apoptosis in the placenta of smoking mothers giving birth to growth-restricted infants and nonsmoking mothers with infants of appropriate weight. The project was conducted at the Magee-Womens Hospital and Magee-Womens Research Institute, University of Pittsburgh, PA. Histological sections from 20 placentas were selected from smoking mothers who had given birth to small-forgestational-age infants (birth weight $\leq 2 \mathrm{SD}$ ). The controls were gestational-age matched nonsmoking mothers with infants having appropriate-for-gestationalage weight. The TUNEL method was used to demonstrate DNA fragmentation in nuclei, and a monoclonal antibody M30, specific for a neo-epitope on cytokeratin 18 , was used to identify apoptotic epithelial cells. The positive nuclei (TUNEL) and positive cells (M30-positive cytoplasm) were counted blindly both in villous tissue and in decidual/basal plate tissue. M30-positive cells in
\end{abstract}

'Deceased April 1, 2003, former address: Valley View Medical Center, 595 South 75 East, Cedar City, UT 84720 , USA.

"Corresponding author, e-mail: christina.isaksen@medisin.ntnu.no villous tissues were significantly increased in placentas from smoking mothers compared to nonsmoking mothers. When evaluated by the TUNEL method, the difference between the two groups of women was not significant. Our study shows that apoptosis was increased in the placentas of smoking mothers with growth-restricted infants. The difference between the two groups was mainly in the syncytiotrophoblast layer and in connection with perivillous fibrin deposition. Cigarette smoke with reduction in blood flow has previously been shown to increase apoptosis, and it is possible that this could be one of the mechanisms playing a role in the growth restriction.

Key words: apoptosis, growth restriction, placenta, pregnancy, smoking

\section{INTRODUCTION}

Pregnant women who smoke are at greater risk of giving birth to a growth-restricted infant, than nonsmoking women [1]. They present a higher rate of perinatal deaths, in addition to an increased risk of spontaneous abortion and preterm delivery $[2,3]$. Women who smoke are also at risk for placentae previa, abruptio placentae, and premature rupture of the membranes [1]. Babies of smokers 
weigh on the average 150-250 g less than nonsmokers' babies. This smoking-related weight reduction is independent of other maternal and infant factors that influence birth weight [1]. The mechanisms leading to intrauterine growth restriction (IUGR) in infants of smoking mothers are not clear. Nicotine and cotinine, a metabolic product of nicotine, both cross the placenta, and a direct toxic action of the components of cigarette smoke on the fetus is one of the most accepted theories explaining the adverse effects of smoking, though not clearly understood [3]. Nicotine is also a potent vasoconstrictor and it is believed that smoking affects intrauterine vessels, with an ensuing constriction contributing to diminished blood flow to the placenta [4]. A direct correlation between fetal oxygen consumption and birth weight has been demonstrated in experimental studies [5]. The fetal growth restriction associated with maternal smoking might therefore be related to chronic hypoxia.

Hypoxia has been hypothesized to induce apoptosis [6]. At the same time, hypoxia has been shown to induce resistance to apoptosis in several cell types, and a significant decrease in neutrophil apoptosis under hypoxic conditions has been demonstrated [7]. Both nicotine and cotinine have been related to the inhibition of apoptosis in both normal and tumor cell cultures [8,9]. Maternal smoking also appears to reduce apoptosis in villous trophoblasts [3], though studies have also shown that nicotine has little effect on cytotrophoblast apoptosis [10].

The proliferation rate of cytotrophoblasts is inversely related to oxygen tension [11]. Since hypoxia has been suggested as the main pathogenic factor in smoking, it is remarkable that no increase in proliferation rate has been observed with maternal smoking [12]. In placentas from mothers who smoked during pregnancy, there is a decreased number of cytotrophoblasts. Recent research has demonstrated that nicotine has a significant negative impact on mitosis, reducing the number of cytotrophoblasts [10]. The placental transfer of amino acids is also impaired in smoking mothers, which may have implications for intrauterine growth restriction [13].

Extensive morphological changes have been observed in placentas of smoking mothers, and oxygenation and the passage of nutrients may be limited by these changes. Since oxygen tension is associated with apoptosis [14], it is reasonable to hypothesize an association between smoking, breaks in the trophoblast covering of the villi with deposition of fibrin, and placental apoptosis $[15,16]$.

Few studies on maternal smoking and placental apoptosis have been conducted $[3,10,17]$. Some controversy exists as to the effect of smoking on apoptosis [3,9, 10, 17,18-20]. Maternal smoking and fetal growth has been extensively studied [1, 2, 21,22-24], though the correlation between intrauterine growth-retarded infants in smoking mothers and placental apoptosis has not been elucidated.

In order to see if intrauterine growth restriction caused by maternal smoking influenced placental apoptosis, we conducted a retrospective study comparing apoptosis in the placenta of smoking mothers giving birth to small-for-gestational-age (SGA) infants and nonsmoking mothers with infants of appropriate-for-gestational-age (AGA) weight.

\section{METHODS}

The project was conducted at the Magee-Womens Hospital and Magee-Womens Research Institute, University of Pittsburgh. The Institutional Review Board at the hospital approved the project.

\section{Tissue specimens}

Cases and controls were selected using the following criteria:

Cases

Twenty placentas from smoking mothers having given birth to an infant with SGA birth weight $\leq 2$ $\mathrm{SD}$, as assessed by standard weight percentiles [25].

\section{Controls}

Twenty placentas from nonsmoking mothers having given birth to an infant with AGA (10th-90th percentile) birth weight.

We could have used other control groups, for example, smokers with normal-weight infants or nonsmokers with growth-restricted infants. In the first category, placental changes are less likely to be expected, and in the second, other reasons for the growth restriction could confound the results. 
Table 1. Clinical information

\begin{tabular}{|c|c|c|c|c|c|c|c|c|c|}
\hline \multicolumn{6}{|c|}{ Smokers with SGA infants } & \multicolumn{4}{|c|}{ NonsmokerswithAGAinfants } \\
\hline No. & Parity & Clinical information & $\begin{array}{l}\text { Smoking } \\
\text { ( } n=\text { cig.) }\end{array}$ & $\begin{array}{l}\text { GA } \\
(w k)\end{array}$ & $\begin{array}{l}\text { Birth } \\
\text { weight } \\
(\mathrm{g})\end{array}$ & Parity & Clinical information & $\begin{array}{l}\text { GA } \\
(w k)\end{array}$ & $\begin{array}{l}\text { Birth } \\
\text { weight } \\
\text { (g) }\end{array}$ \\
\hline 1 & G1P0 & Severe IUGR & 20 & 33.4 & 1164 & G5P3 & Placenta previae & 33.0 & 2412 \\
\hline 2 & G3P2 & IUGR & 20 & 38.0 & 1915 & G3P2 & Normal pregnancy & 37.2 & 3108 \\
\hline 3 & G3P2 & Asthma & 10 & 41.0 & 2505 & G3P2 & Placenta previae & 41.1 & 3833 \\
\hline 4 & G5P4 & IUGR & + & 36.0 & 1406 & G3P1 & PROM & 36.0 & 2398 \\
\hline 5 & $\mathrm{G} 2 \mathrm{P} 1$ & Tetralogy of Fallot & 20 & 37.0 & 2359 & G3P2 & Placenta previae & 37.0 & 2844 \\
\hline 6 & G3P1 & IUGR, Rh- & 20 & 39.0 & 2727 & $\mathrm{G} 2 \mathrm{P} 1$ & Normal pregnancy & 39.0 & 3089 \\
\hline 7 & G1P0 & IUGR, asthma & 20 & 38.0 & 2130 & G3P1 & Placenta previae & 37.1 & 3461 \\
\hline 8 & G3P2 & IUGR, asthma & 15 & 36.5 & 1743 & G1P0 & PROM & 35.0 & 2395 \\
\hline 9 & $\mathrm{G} 2 \mathrm{P} 1$ & IUGR & 20 & 38.6 & 2361 & $\mathrm{G} 2 \mathrm{P} 0$ & Maternal fever & 40.1 & 3120 \\
\hline 10 & $\mathrm{G} 2 \mathrm{P} 0$ & IUGR & 8 & 38.0 & 2351 & $\mathrm{G} 2 \mathrm{P0}$ & Normal pregnancy & 38.6 & 2951 \\
\hline 11 & G3P2 & IUGR, Rh-, drug abuse & 15 & 35.6 & 1728 & $\mathrm{G} 2 \mathrm{P} 1$ & Fetal distress & 35.0 & 2345 \\
\hline 12 & G1P0 & PROM, fetal distress & 20 & 29.1 & 668 & G4P2 & Cerclage PROM & 28.6 & 1462 \\
\hline 13 & G1P0 & Drug abuse & 40 & 38.4 & 2228 & G5P2 & Normal pregnancy & 39.0 & 3640 \\
\hline 14 & $\mathrm{G} 2 \mathrm{P} 0$ & IUGR & 10 & 38.0 & 2183 & G1P0 & Normal pregnancy & 38.0 & 3246 \\
\hline 15 & $\mathrm{G} 2 \mathrm{P} 1$ & IUGR & 40 & 38.0 & 2138 & $\mathrm{G} 2 \mathrm{P} 1$ & PROM & 38.0 & 3510 \\
\hline 16 & G2P1 & IUGR, fetal distress & 15 & 35.0 & 1212 & G2P1 & Placenta previae & 35.0 & 2276 \\
\hline 17 & G1P0 & IUGR & + & 37.3 & 2196 & $\mathrm{G} 2 \mathrm{P} 1$ & Placenta previae & 37.0 & 3012 \\
\hline 18 & G1P0 & IUGR & 10 & 37.0 & 2257 & G1P0 & Placenta previae & 37.0 & 2979 \\
\hline 19 & G2P0 & Severe IUGR & 10 & 25.1 & 791 & $\mathrm{G} 2 \mathrm{P0}$ & Placenta previae & 26.0 & 850 \\
\hline 20 & $\mathrm{G} 2 \mathrm{P} 0$ & Asthma & 20 & 36.4 & 1626 & G3P2 & Placenta previae & 36.4 & 3093 \\
\hline
\end{tabular}

SGA, small-for-gestational-age; AGA, appropriate-for-gestational-age; G, gravida; P, para; cig., cigarettes; GA, gestational age; wk, weeks; PROM, premature rupture of the membranes; IUGR, intrauterine growth restriction.

Previous studies have shown that apoptosis increases towards term $[26,27]$. The controls and cases were therefore matched for gestational age.

Information was obtained by using the database at the Department of Pathology. All reports were from the period 1996 to 2000 , and supplementary clinical information was pulled from the hospital records.

Placentas from women with preeclampsia, gestational hypertension, diabetes, infection, or any other serious illness were excluded from the study. Placentas from infants with serious or multiple developmental anomalies, and placentas with chorioamnionitis or extensive villitis, were also excluded. Clinical data on both groups are given in Table 1. The results of the morphological examination of placental tissue are shown in Table 2.

Two formalin-fixed and paraffin-embedded blocks were retrieved from each placenta, one from the periphery and one central. Five micronthick sections were cut from each block. In order to evaluate apoptosis, both the TUNEL method and immunohistochemistry with a M30 antibody were performed.

\section{TUNEL method}

A DNA fragmentation kit was used for the TUNEL (terminal deoxynucleotidyl transferase-mediated deoxyuridine triphosphate [dUTP] nick end labeling) staining (Oncogene Research Products, Boston, MA). The nick end labeling refers to staining of the DNA 3' hydroxy groups generated as a result of endonuclease activity at linker DNA regions between nucleosomes. The commercially given instructions were followed. TUNEL-positive nuclei stained dark brown, and when they also looked pyknotic, they were regarded as apoptotic. Sections from human lymph node were included in all 


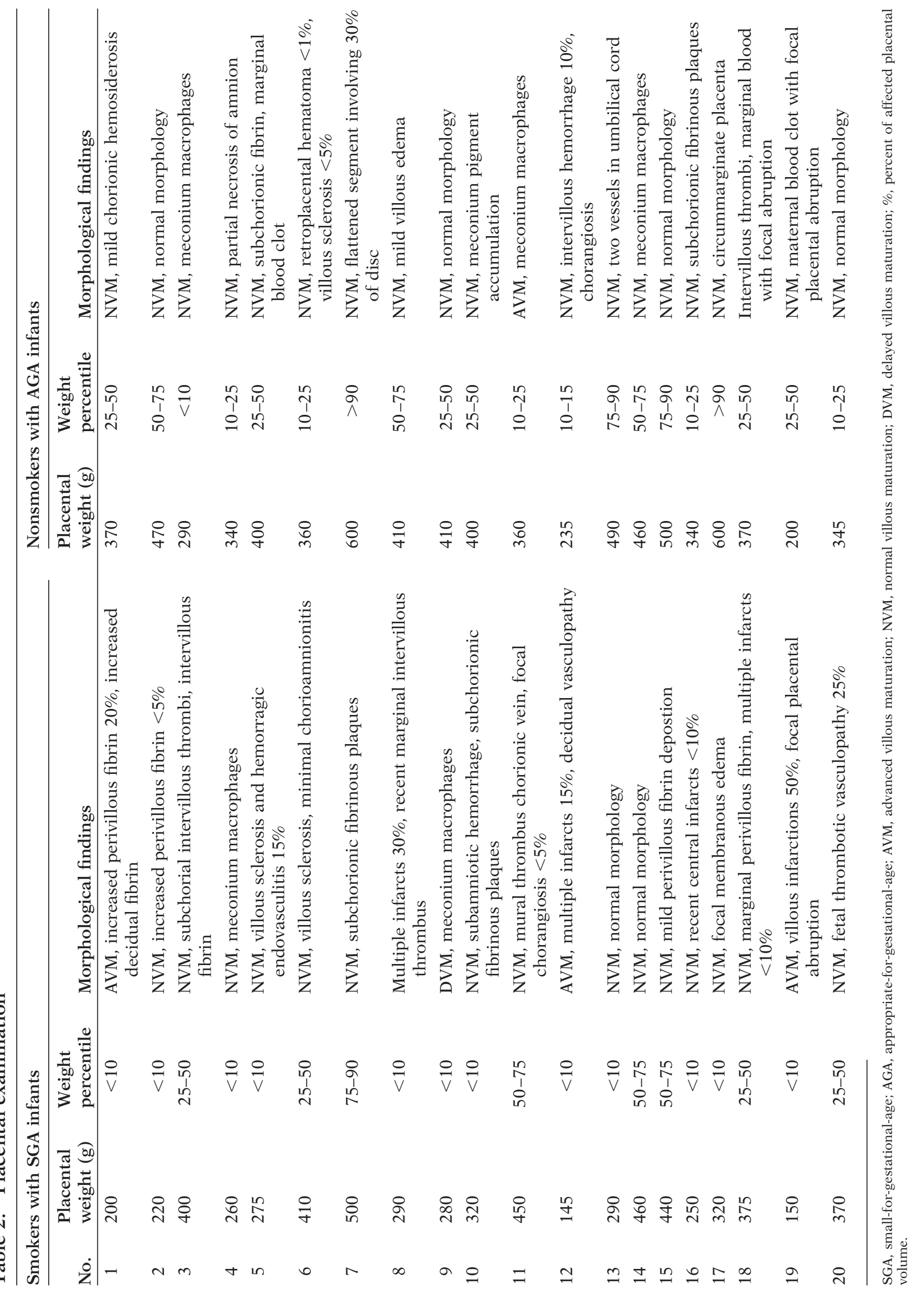


batches as positive controls. Sections from placental tissue, to which addition of enzyme was replaced by distilled water, served as negative controls.

\section{Immunostaining with the monoclonal antibody M30}

The monoclonal antibody (mab) M30 (Boehringer Mannheim, Mannheim, Germany), specific for a neo-epitope on cytokeratin 18 (CK18), was used to recognize apoptotic epithelial cells $[28,29]$. CK 18 is cleaved by caspases early in the apoptotic cascade, thus visualizing apoptosis before DNA fragmentation detectable by the TUNEL method. Immunostaining with M30 was performed as previously described [30]. Sections from an adenocarcinoma of colon were added as positive controls [31]. M30 positivity gives a cytoplasmic staining, most often homogeneous, but sometimes more granular. Cells with pyknotic nuclei and red staining of cytoplasm were regarded as apoptotic. The TUNEL method and the mab M30 immunostaining were performed on serial slides from each placenta, and all the slides were blinded. The coded slides were selected in such a way that the gestational age-matched cases and controls were included in the same batch.

\section{Quantification of apoptosis}

TUNEL-positive nuclei and M30-positive cells were counted blindly according to the criteria given above. Twenty fields of villous tissue at $200 \times$ magnification and 20 fields of maternal basal plate tissue at $400 \times$ magnification were counted on each slide, though on a number of slides there was not sufficient basal plate tissue to count 20 fields. Only fields with at least $80 \%$ tissue coverage were evaluated. The localization and origin of the positive cells were taken into consideration and categorized thereafter. When TUNEL-positive nuclei and M30-positive cells in all slides were counted, the code was broken. Cells from the peripheral and central sections were added to each other so that altogether 40 fields of villous tissue from each placenta were evaluated. With M30 immunohistochemistry, the number of fields in decidual/basal plate tissue varied from 4 to 36 , with 18 as the median, with interquartile ranges (IQR) corresponding to $25-75 \%$ of $12.0-24.0$. For the TUNEL method, the number of fields varied from 15 to 40 , with 40 as the median, IQR $25-75 \%$ of $31.3-40$. The number of M30- and TUNEL-positive cells per field was calculated, and the rate of apoptosis in villous and decidual/basal plate tissue is shown in Table 3.

\section{Statistical analysis}

It was calculated that to obtain a statistical power of $90 \%$, study groups of 20 were needed. Sample size calculations were performed on the Number Cruncher Statistical Systems (NCSS) program (Hintze J [2001] Kaysville, UT, USA). The apoptotic rate showed a marked skewed distribution towards zero, therefore median group values were employed with corresponding IQR and application of nonparametric statistics. In order to evaluate differences in apoptotic rate between the matched groups, $P$-values were calculated by using Wilcoxon signed-rank test for paired data. For unmatched comparison, the Mann-Whitney $U$-test was applied. Statistical analyses were performed using Statistical Package for Social Services (SPSS) version 11 (SPSS for Windows, SPSS Inc., Chicago, IL, USA).

\section{RESULTS}

M30-positive cells showed either a homogenous or granular red cytoplasmic staining (Fig. 1A). Positive syncytiotrophoblasts were either located on the villous surface, as syncytial knots (Fig. 1B), or lying in connection with peri- and intervillous fibrin deposition (Fig. 1C). Like the M30 positivity, TUNEL-positive nuclei were found in the villous syncytiotrophoblast layer (Fig. 2A), in syncytial knots (Fig. 2B), and in connection with fibrin deposition (Fig. 2C).

Total cell number in fields of villous tissue ( $n$ $=5$ ) was counted in order to calculate the percentage of apoptotic cells. The median number was 840, IQR: $816-833$. If 840 represents the total cell number in the evaluated villous field, the total apoptotic rate in villous tissue of controls as evaluated by M30 was estimated as $0.04 \%$, IQR: 0.02 $0.07 \%$.

Table 3 shows the number of apoptotic cells per field in various placental tissues as assessed by immunostaining with the M30 antibody. M30 positivity was significantly increased in villous tissue 
Table 3. Number of apoptotic cells per field in various placental tissues as assessed by mab M30

\begin{tabular}{|c|c|c|c|c|c|}
\hline Tissue & Group & Median $^{a}$ & 25 th & 75th & $P$-value* \\
\hline \multirow[t]{2}{*}{ Villous tissue } & Smokers & 0.56 & 0.48 & 0.96 & 0.04 \\
\hline & Controls & 0.35 & 0.18 & 0.63 & - \\
\hline \multirow[t]{2}{*}{ Syncytiotrophoblast layer } & Smokers & 0.13 & 0.08 & 0.20 & 0.50 \\
\hline & Controls & 0.10 & 0.05 & 0.15 & - \\
\hline \multirow[t]{2}{*}{ Peri/intervillous fibrinoid } & Smokers & 0.38 & 0.16 & 0.73 & 0.17 \\
\hline & Controls & 0.19 & 0.08 & 0.44 & - \\
\hline \multirow[t]{2}{*}{ Villous stroma } & Smokers & 0.03 & 0.01 & 0.05 & 0.49 \\
\hline & Controls & 0.04 & 0.01 & 0.07 & - \\
\hline \multirow[t]{2}{*}{ Decidual/basal plate } & Smokers & 0.61 & 0.24 & 0.67 & 0.10 \\
\hline & Controls & 0.38 & 0.09 & 0.66 & - \\
\hline \multirow[t]{2}{*}{ Anchoring villi } & Smokers & 0.10 & 0.04 & 0.22 & 0.42 \\
\hline & Controls & 0.10 & 0.00 & 0.20 & - \\
\hline \multirow[t]{2}{*}{ Extravillous trophoblasts } & Smokers & 0.33 & 0.13 & 0.56 & 0.06 \\
\hline & Controls & 0.23 & 0.00 & 0.41 & - \\
\hline \multirow[t]{2}{*}{ All tissues combined } & Smokers & 1.10 & 0.79 & 1.41 & 0.10 \\
\hline & Controls & 0.79 & 0.27 & 1.40 & - \\
\hline
\end{tabular}

(including syncytiotrophoblasts and peri/intervillous fibrin) in placentas from smoking mothers with SGA infants compared to nonsmoking mothers with normal infants. Generally, the M30 count was higher in the smoking group compared to the control group, though except for total villous tissue, this difference was not significant. There was no significant difference between the two groups of women with regard to apoptosis as evaluated by the TUNEL method. This pertains to all types of tissue counted: syncytiotrophoblasts, fibrin, villous stroma, anchoring villi, and extravillous trophoblasts.

In decidual/basal plate tissue, M30-positive extravillous cytotrophoblasts and TUNEL-positive nuclei were detected. Since M30 positivity occurs in epithelial cells, it was not relevant to compare the decidual cells. There was an increased number of M30-positive cells in extravillous trophoblasts ( $P$ $=0.06$ ) but not in anchoring villi in smokers as compared to controls (Table 3).

Morphological alterations in the placenta were more frequent in placentas of smoking mothers (Table 2). Advanced villous maturation was described in one case in the control group and in three cases in the smoking group. Peri/intervillous fibrin deposition or infarcts were found in 10 of the smoking cases, while in none of the control group. Five cases were described as largely normal in the smoking group, while 15 were described as normal in the control group.

\section{DISCUSSION}

Two major reasons for the intrauterine growth restriction in infants of smoking mothers have been proposed, namely toxic effects of nicotine and its metabolites, and a vasoconstrictor effect causing diminished blood flow to the placenta with fetal hypoxia [4]. The placenta retains substantial amounts of compounds from cigarette smoke, both in their native forms and in intracellular substrates [32,33]. Cotinine levels in plasma have been shown to correlate with uteroplacental vascular resistance estimated from blood flow velocity measures by Doppler [4,34].

What is then the link to apoptosis? Apoptosis, or programmed cell death, was first described by Kerr et al. [35]. It is a normal physiological form of cell death, that together with mitosis, has the function of controlling cell population $[26,36]$. The pro- 


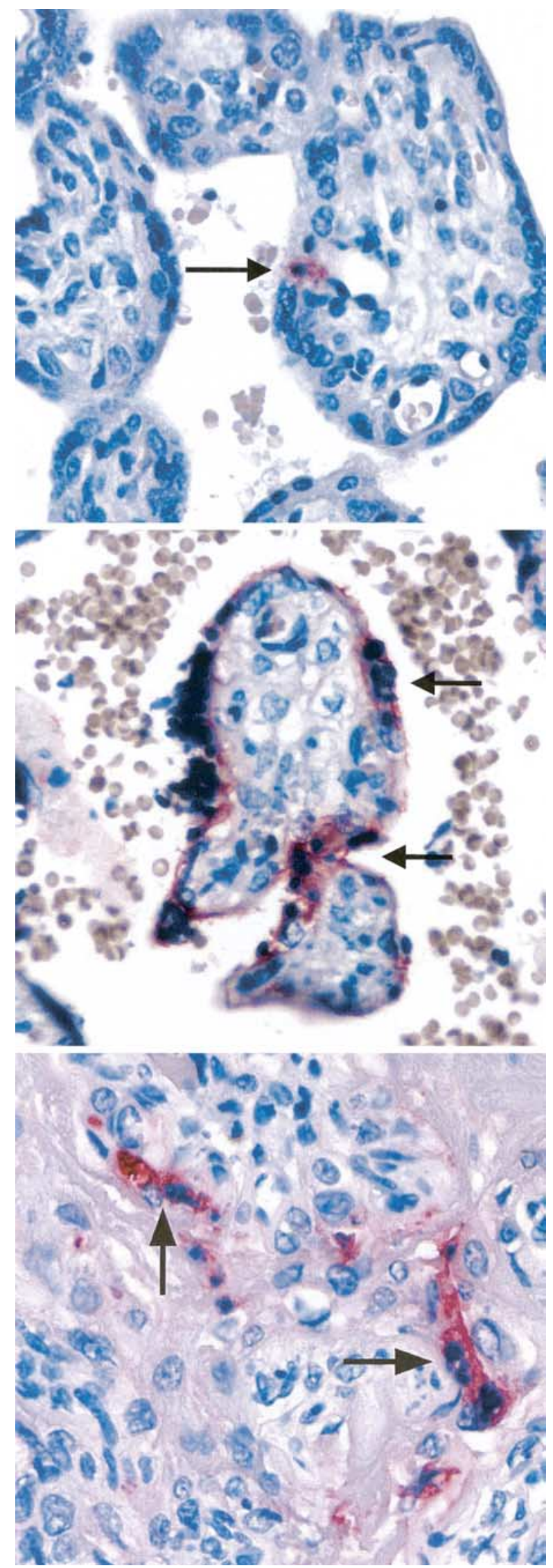

Figure 1. M30-positive cells. A. Homogenous or granular red cytoplasmic staining. B. Positive syncytiotrophoblasts. C. Positive cells in fibrin.

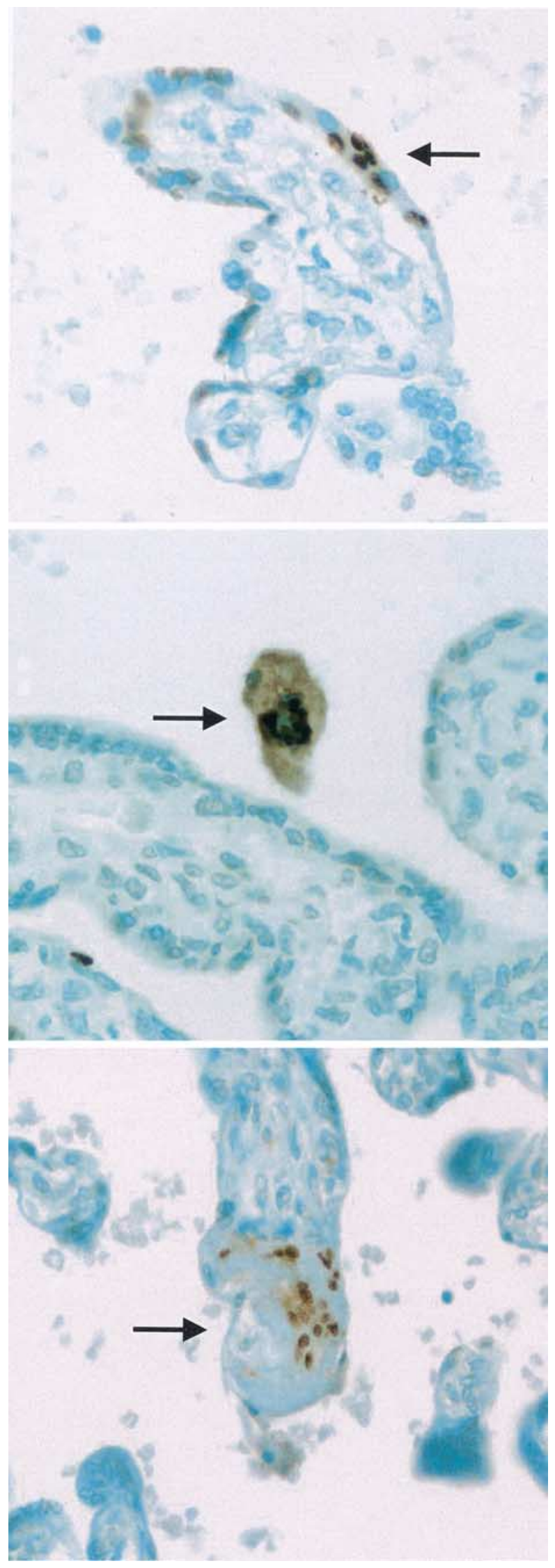

Figure 2. TUNEL-positive nuclei. A. In villous syncytiotrophoblast layer. B. In syncytial knots. C. In connection with fibrin deposition. 
cess may be influenced by different stimuli, both physiological and nonphysiological [37].

Nicotine has been related to the inhibition of apoptosis in cell cultures [8,9], while hypoxia has been shown to induce apoptosis [6,38,39]. Enhancement of apoptosis by hypoxia has also been demonstrated in cultured human trophoblasts, while addition of epidermal growth factor (EGF) to the cultures lowers the level of apoptosis [39], suggesting that EGF may protect against apoptosis induced by hypoxia.

Cigarette smoke has also been shown to increase apoptosis in the gastric mucosa of rats, by reducing gastric blood flow, thus decreasing serum epidermal growth factor $[19,20]$. Could the same mechanisms play a role in the uterus, with a decrease in serum EGF implicated in the intrauterine growth restriction? Other studies have not shown increased apoptosis in placentas of smoking mothers [3], however, these have not taken into account whether the infants were growth restricted or not.

Increased apoptosis has been found in placentas of pregnancies complicated by fetal growth restriction [40]. We also found a significant increase of apoptosis in villous tissue in the placentas of smoking mothers who delivered a growthrestricted infant. This increase could be explained by hypoxia accentuated by reduced blood flow with decrease in EGF. Since EGF is present in amniotic fluid [41], the IUGR found in children of smoking mothers might be a direct effect of decreases in EGF levels either in serum or amniotic fluid. Nicotine has also been shown to have an inhibitory effect on early trophoblast differentiation [10,42], and the increased apoptosis may, in part, be due to a direct toxic effect of the components of cigarette smoke [3].

Apoptosis, as evaluated by the TUNEL method, was not significantly increased as compared to controls. Completely normal controls for the various gestational ages were difficult to find, and altogether nine cases had placenta previae. Some of these placentas had higher TUNEL counts than M30, which we ascribe to the fact that TUNEL staining is not specific for apoptosis, but also stains necrotic cells [43]. It is therefore important to take into account false-positive TUNEL staining. With the M30 antibody, there was little nonspecific staining present, and we recommend the use of this antibody when studying apoptosis in CK18-positive epithelial cells.

In smoking mothers, the placental/fetal ratio is increased and morphological alterations have been demonstrated $[42,44]$. In our study, infarcts or peri/intervillous fibrin deposition were registered in $50 \%$ of cases in the smoking group, with none in the control group. Fibrinoid deposition during gestation occurs at sites of trophoblast discontinuity, it is nonrandom and influenced by the quality of vascular perfusion $[16,45,46]$. Smoking during pregnancy affects placental blood flow $[47,48]$, therefore, the morphological findings in placentas of smoking mothers do not seem to be haphazard, but related to the effects of cigarette smoke.

During the first trimester, focal defects in floating villi with absence of cytotrophoblast stem cells have been demonstrated, together with an increase in the number of cytotrophoblast columns that fail to reach the uterus or degenerate in the intervillous space, implying a reduction in the number of anchoring villi [10]. A reduced number of Ki-67-positive cytotrophoblasts means that fewer cells are in the S-phase causing a premature depletion of cytotrophoblast stem cell population [10]. We can thus conclude that the cytotrophoblast population in placentas of smoking mothers is reduced. When apoptosis among these cytotrophoblasts is increased, this will further diminish blood flow and oxygenation potential over the fetal-maternal membrane, also decreasing EGF and escalating the nutritional defects to the fetus.

\section{CONCLUSION}

Our study shows that apoptosis in fetal villous tissue is increased in the placentas of smoking mothers with SGA infants compared to gestationmatched controls with AGA infants and mothers who do not smoke. Increased peri/intervillous fibrin deposition was found in the smoking group, but not in the control group. The role of hypoxia in the induction of apoptosis has previously been demonstrated. Apoptosis in syncytiotrophoblasts causes discontinuities in the trophoblast layer and deposition of fibrin-type fibrinoid, which further reduces factors implicated in growth. 


\section{ACKNOWLEDGMENTS}

The authors thank Professor Steinar Tretli for his help concerning calculations of statistical power and study group size.

Grant support was provided by the Research Council of Norway. The work was performed at Magee-Womens Hospital and Magee-Womens Institute, University of Pittsburgh, Pittsburgh, PA, USA.

\section{REFERENCES}

1. Meyer MB, Tonascia JA. Maternal smoking, pregnancy complications, and perinatal mortality. Am J Obstet Gynecol 1977;128:494-502.

2. Meyer MB, Jonas BS, Tonascia JA. Perinatal events associated with maternal smoking during pregnancy. Am J Epidemiol 1976;103:464-475.

3. Marana HRC, Andrade JM, Martins GA, Silva JS, Sala MA, Cunha SP. A morphometric study of maternal smoking on apoptosis in the syncytiotrophoblast. Int J Gynaecol Obstet 1998;61:21-27.

4. Castro LC, Allen R, Ogunyemi D, Roll K, Platt LD. Cigarette smoking during pregnancy: acute effects on uterine flow velocity waveforms. Obstet Gynecol 1993;81:551-555.

5. Caton D, Henderson DJ, Wilcox CJ, Barron DH. Oxygen consumption of the uterus and its contents and weight at birth of lambs. In: The American Physiological Society Satellite Symposium: Fetal and Newborn Cardiovascular Circulation. New York: Garland STPM Press, 1976; 10: 123133.

6. Muschel RJ, Bernhard EJ, Garza L, McKenna WG, Koch CJ. Induction of apoptosis at different oxygen tensions: evidence that oxygen radicals do not mediate apoptotic signaling. Cancer Res 1995;55:995-998.

7. Hannah S, Mecklenburgh K, Rahman I, et al. Hypoxia prolongs neutrophil survival in vitro. FEBS Lett 1995;372:233237.

8. Aoshiba K, Nagai A, Yasui S, Konno K. Nicotine prolongs neutrophil survival by suppressing apoptosis. J Lab Clin Med 1996;127:186-194.

9. Wright SC, Zhong J, Zheng H, Larrick JW. Nicotine inhibition of apoptosis suggests a role in tumor promotion. FASEB J 1993; 7:1045-1051.

10. Genbacev O, McMaster MT, Lazic J, et al. Concordant in situ and in vitro data show that maternal cigarette smoking negatively regulates placental cytotrophoblast passage through the cell cycle. Reprod Toxicol 2000;14:495-506.

11. Fox H. The villous cytotrophoblast as an index of placental ischemia. J Obstet Gynecol B Commonwealth 1964;71:885893.

12. Arnholdt H, Meisel F, Fandrey K, Löhrs U. Proliferation of villous trophoblast of the human placenta in normal and abnormal pregnancies. Virchows Archiv [B] 1991;60:365372.

13. Pastrakuljic A, Derewlany LO, Koren G. Maternal cocaine use and cigarette smoking in pregnancy in relation to amino acid transport and fetal growth. Placenta 1999;20: 499-512.

14. Yun JK, McCormick TS, Judware R, Lapetina EG. Cellular adaptive responses to low oxygen tension: apoptosis and resistance. Neurochem Res 1997;22:517-521.

15. Nelson DM, Crouch EC, Curran EM, Farmer DR. Trophoblast interaction with fibrin matrix. Epithelialization of perivillous fibrin deposits as a mechanism for villous repair in the human placenta. Am J Pathol 1990;136:855-865.

16. Nelson DM. Apoptotic changes occur in syncytiotrophoblast of human placental villi where fibrin type fibrinoid is deposited at discontinuities in the villous trophoblast. Placenta 1996;17:387-391.

17. Gruslin A, Qiu Q, Tsang BK. Influence of maternal smoking on trophoblast apoptosis throughout development: possible involvement of Xiap regulation. Biol Reprod 2001;65:11641169.

18. Banzet N, Francois D, Polla BS, Cho CH. Tobacco smoke induces mitochondrial depolarization along with cell death: effects of antioxydants. Redox Rep 1999;4:229-236.

19. Wang HY, Ma L, Li Y, Cho CH. Exposure to cigarette smoke increases apoptosis in the rat gastric mucosa through a reactive oxygen species-mediated and P53-independent pathway. Free Radic Biol Med 2000;28:1125-1131.

20. Ma L, Wang HY, Chow JYC, Cho CH. Cigarette smoke increases apoptosis in the gastric mucosa: role of epidermal growth factor. Digestion 1999;60:461-468.

21. Matsubara F, Kida M, Tamakoshi A, Wakai K, Kawamura T, Ohno Y. Maternal active and passive smoking and fetal growth: a prospective study in Nagoya, Japan. J Epidemiol 2000;10:335-343.

22. Chan A, Keane RJ, Robinson JS. The contribution of maternal smoking to preterm birth, small for gestational age and low birthweight among Aboriginal and non-Aboriginal births in South Australia. Med J Aust 2001;174:389-393.

23. Hruba D, Kachlik P. Influence of maternal active and passive smoking during pregnancy on birthweight in newborns. Cent Eur J Public Health 2000;8:249-252.

24. Andres RL, Day MC. Perinatal complications associated with maternal tobacco use. Semin Neonatol 2000;5:231241.

25. Usher R, McLean F. Intrauterine growth of live-born Caucasian infants at sea level: standards obtained from measurements in 7 dimensions of infants born between 25 and 44 weeks of gestation. J Pediatr 1969;74:901-910.

26. Smith SC, Baker PN, Symonds EM. Placental apoptosis in normal human pregnancy. Am J Obstet Gynecol 1997;177: 57-65.

27. Smith SC, Leung TN, To KF, Baker PN. Apoptosis is a rare event in first-trimester placental tissue. Am J Obstet Gynecol 2000;183:697-699.

28. Caulin C, Salvesen GS, Oshima RG. Caspase cleavage of keratin 18 and reorganization of intermediate filaments during epithelial cell apoptosis. J Cell Biol 1997;138:13791394.

29. Kadyrov M, Kaufmann P, Huppertz B. Expression of a cytokeratin 18 neo-epitope is a specific marker for trophoblast apoptosis in human placenta. Placenta 2001;22:4448 .

30. Austgulen R, Chedwick L, Vogt Isaksen C, Vatten L, Craven C. Trophoblast apoptosis in human placenta at term as detected by expression of a cytokeratin 18 degradation product of caspase. Arch Pathol Lab Med 2002;126:14801486.

31. Carr NJ. M30 expression demonstrates apoptotic cells, correlates with in situ end-labeling, and is associated with Ki-67 expression in large intestinal neoplasms. Arch Pathol Lab Med 2000;124:1768-1772.

32. Rama Sastry BV, Chance MB, Hemontolor ME, GoddijnWessel TAW. Formation and retention of cotinine during placental transfer of nicotine in human placental cotyledon. Pharmacology 1998;57:104-116.

33. Arnould JP, Verhoest P, Bach V, Libert JP, Belegaud J. Detection of benzo(a)pyrene-DNA adducts in human pla- 
centa and umbilical cord blood. Hum Exp Toxicol 1997;16: $716-721$.

34. Lymperopoulou A, Hainaut F, Crimail P, Durand J-L, Locatelli C, Maison C. Tabac et grossesse: recherche d'une corrélation cotininémie et Doppler. [Smoking and pregnancy: search for a correlation between cotidinemia and Doppler findings]. J Gynecol Obstet Biol Reprod 1996;25: 824-827.

35. Kerr JF, Wyllie AH, Currie AR. Apoptosis: a basic biological phenomenon with wide-ranging implications in tissue kinetics. Br J Cancer 1972;26:239-257.

36. Gerschenson LE, Rotello RJ. Apoptosis: a different type of cell death. FASEB J 1992;6:2450-2455.

37. Williams GT, Smith CA. Molecular regulation of apoptosis: genetic controls on cell death. Cell 1993;74:777-779.

38. Allen J, Winterford C, Axelsen RA, Gobé GC. Effects of hypoxia on morphological and biochemical characteristics of renal epithelial cell and tubule cultures. Ren Fail 1992; 14:453-460.

39. Levy R, Smith SD, Chandler K, Sadovsky Y, Nelson DM. Apoptosis in human cultured trophoblasts is enhanced by hypoxia and diminished by epidermal growth factor. Am J Physiol Cell Physiol 2000;278:C982-C988.

40. Smith SC, Baker PN, Symonds EM. Increased placental apoptosis in intrauterine growth restriction. Am J Obstet Gynecol 1997;177:1395-1401.
41. Fischer DA. Hormone epidermal growth factor interactions in development. Horm Res 1990;33:69-75.

42. Genbacev O, Bass KE, Joslin RJ, Fisher SJ. Maternal smoking inhibits early human cytotrophoblast differentiation. Reprod Toxicol 1995;9:245-255.

43. Yasuda M, Umemura S, Osamura RY, Kenjo T, Tsutsumi Y. Apoptotic cells in the human endometrium and placental villi: pitfalls in applying the TUNEL method. Arch Histol Cytol 1995;58:185-190.

44. Shiverick KT, Salafia C. Cigarette smoking and pregnancy I: ovarian, uterine and placental effects. Placenta 1999;20: 265-272.

45. Mayhew TM, Bowles C, Orme G. A stereological method for testing whether or not there is random deposition of perivillous fibrin-type fibrinoid at the villous surface: description and pilot applications to term placentae. Placenta 2000;21: 684-692.

46. Mayhew TM, Barker BL. Villous trophoblast: morphometric perpectives on growth, differentiation, turnover and deposition of fibrin-type fibrinoid during gestation. Placenta 2001;22:628-638.

47. Bush PG, Mayhew TM, Abramovich DR, Aggett PJ, Burke MD, Page KR. Maternal cigarette smoking and oxygen diffusion across the placenta. Placenta 2000;21:824-833.

48. Larsen LG, Clausen HV, Jønsson L. Stereologic examination of placentas from mothers who smoke during pregnancy. Am J Obstet Gynecol 2002;186:531-537. 